\title{
CYTOTOXICITY EVALUATION OF 63S BIOACTIVE GLASS AND BONE-DERIVED HYDROXYAPATITE PARTICLES USING HUMAN BONE-MARROW STEM CELLS
}

\author{
Ali Doostmohammadi ${ }^{\mathrm{a}, \mathrm{b} *}$, Ahmad Monshi ${ }^{\mathrm{a}}$, Rasoul Salehic, Mohammad Hossein Fathi ${ }^{\mathrm{a}}$, \\ Ehsan Seyedjafari $^{\mathrm{d}}$, Abbas Shafiee ${ }^{\mathrm{e}}$, Masoud Soleimani ${ }^{\mathrm{f}}$
}

\author{
a Biomaterials Group, Department of Materials Engineering, Isfahan University of Technology, Isfahan, 84156-83111, Iran \\ ${ }^{b}$ Isfahan University of Medical Science, Isfahan, 81746-73461, Iran \\ c Department of Genetics and Molecular Biology, School of Medicine, Isfahan University of Medical Sciences, Isfahan, \\ 81746-73461, Iran \\ d Department of Biotechnology, College of Science, University of Tehran, Tehran, Iran \\ e Stem cell Biology department, Stem cell technology research center, Tehran, Iran \\ $f$ Department of hematology, Faculty of Medical Sciences, Tarbiat modares University, Tehran, Iran \\ E-mail:alidm14@ma.iut.ac.ir
}

Received: January 29, 2011; Accepted with revision: April 18, 2011; Available online: May 9, 2011

Key words: Bioactive glass/Bone-derived hydroxyapatite/Human bone-marrow stem cells/Cytotoxicity

Background. In recent years, bioceramics have been favored by biomaterials scientists and researchers. Due to their special and distinctive features, bioactive glass and hydroxyapatite possess a higher place among different types of bioceramics.

Method. In this study, the effect of 63S bioactive glass and bone-derived hydroxyapatite particles on the proliferation of human bone-marrow stem cells (hMSCs) was investigated. Bioactive glass particles were made via sol-gel method and hydroxyapatite was obtained from bovine bone. The particle size and morphology were investigated by scanning electron microscope (SEM). Then the in vitro cytotoxicity of particles was evaluated using MTT assay. SEM showed that bioactive glass particles were in the nanoscale range and had tendency towards agglomeration. It was also confirmed that the hydroxyapatite particles were agglomerations of crystals cca 50-500 nm across.

Results. The results of MTT assay confirmed the viability and proliferation of hMSCs in contact with bioactive glass and bone-derived HA particles. The fabricated particles in combination with stem cells were shown to hold promising potential for further applications in tissue engineering and regenerative medicine.

\section{INTRODUCTION}

A growing interest has arisen in the application of bioceramics as implant materials ${ }^{1}$. In comparison with metallic and polymeric biomaterials, bioceramics reveal excellent biocompatibility and considerable bioactivity ${ }^{1}$. Due to their special and distinctive features, bioactive glass and hydroxyapatite possess a higher place among different types of bioceramics ${ }^{1,2}$. Many researchers around the world have exclusively focused on these materials; and their application in the human body is still expanding ${ }^{1,2}$. Bioactive glass has the potential for bone replacement graft material and has the effectiveness of an adjunct to intrabony defects ${ }^{3}$. Additionally, recent findings have demonstrated that there is a genetic control of the cellular response to bioactive glass materials ${ }^{4}$. These findings indicate that bioactive glass materials are very engaging options for tissue regeneration and tissue engineering. Hydroxyapatite (HA), $\left[\mathrm{Ca}_{10}(\mathrm{PO} 4)_{6}(\mathrm{OH})_{2}\right]$, products are notable as implantable ceramics for hard tissue reconstitution ${ }^{5,6}$. Hydroxyapatite supports osteoconduction ${ }^{6}$, and after implantation and over time, HA materials derived from both natural and synthetic sources can gradually make a strong bounding to human bone tissue but bone-derived HA can retain bone's trace elements and the crystals of bone-derived $\mathrm{HA}$ are near to the normal crystal size of HA in bone ${ }^{6,7}$.

Recently, human mesenchymal stem cells (hMSCs) have been considered as an ideal source for cell-based therapies and tissue engineering ${ }^{8}$. They have a potential for differentiation into osteoblasts, chondrocytes and adipocytes. They are also easily accessible with less ethical issues than other types of stem cells ${ }^{9}$. There are many studies which have suggested bioceramics for tissue regeneration. In this approach, it is a key issue to evaluate the effect of the newly developed bioceramics on the viability and proliferation of stem cells $\mathrm{s}^{10,11}$.

There is no published information concerning the cytotoxic effect of bone-derived HA and 63S bioglass particles on the proliferation of hMSCs. In this study, first there would be a description of how the $63 \mathrm{~S}$ bioactive glass and bone-derived HA particles were prepared. Then, the effect of these bioceramics on the proliferation of hMSCs was evaluated using MTT assay. 


\section{MATERIALS AND METHODS}

\section{Synthesis and preparation}

\section{Bioactive glass}

Colloidal solutions (sols) of $63 \mathrm{~S}$ composition ( $63 \mathrm{~mol} \% \mathrm{SiO}_{2}, 28 \mathrm{~mol} \% \mathrm{CaO}, 9 \mathrm{~mol} \% \mathrm{P}_{2} \mathrm{O}_{5}$ ) were prepared by mixing distilled water, $2 \mathrm{M}$ hydrochloric acid, tetraethyl orthosilicate (TEOS), triethyl phosphate (TEP) and calcium nitrate ${ }^{12}$. The initial procedure involved mixing TEOS $(28 \mathrm{ml})$ and ethanol $(40 \mathrm{ml})$ as an alcoholic media. Distilled water was added to the solution and allowed to mix until the solution became clear. The H2O:(TEOS) molar ratio was 4:1. After 30 min, TEP $(2.3 \mathrm{ml})$ added to the stirring solution. After another 20 min, calcium nitrate ( $12 \mathrm{~g}$ ) was added. The solution was then stirred for an additional hour. The gel was heated $\left(60{ }^{\circ} \mathrm{C}, 10 \mathrm{~h}\right)$, dried $\left(130{ }^{\circ} \mathrm{C}, 15 \mathrm{~h}\right)$ and thermally stabilized $\left(600{ }^{\circ} \mathrm{C}, 2 \mathrm{~h}\right)\left(\right.$ ref. $\left.{ }^{12}\right)$. (Fig. 1) shows the flow chart of bioglass synthesis by the sol-gel method. The produced glass was ground with a mortar and pestle to disagglomerate the particles. Finally the particles were sieved to make a distribution of particle size less than $1 \mu \mathrm{m}$ (L3-M1 $1 \mu \mathrm{m}$ stainless steel sieve \& Sonic Sifter Separator, Advantech Manufacturing Co., USA).

\section{Bone-derived $H A$}

A femur of an adult bovine was boiled in water for $12 \mathrm{~h}$ to render it aseptic and loosen any attached soft tissues. Then it was washed and cleaned carefully to remove visible tissues and fats on the bone surface. To remove the internal organic content, the bone was then heated $\left(700{ }^{\circ} \mathrm{C}, 2 \mathrm{~h}\right)$ in an electric furnace under ambient conditions. The resulting white solid specimens were ground

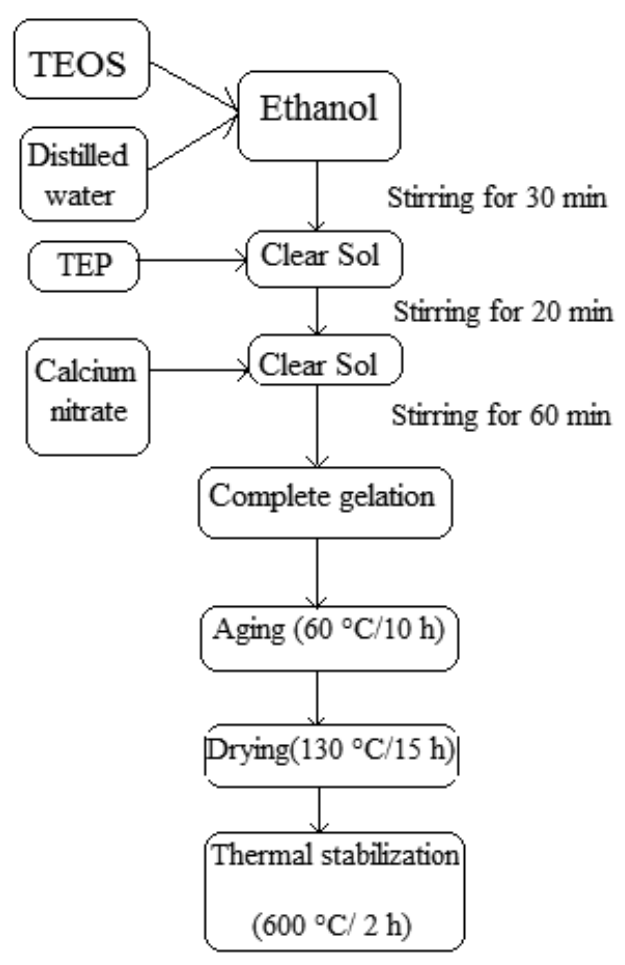

Fig. 1. Flow chart of synthesis of bioactive glass powder. and crushed with a mortar and pestle to produce a powder. The powder was then sieved to produce a distribution of particle size less than less than $1 \mu \mathrm{m}$ (L3-M1 $1 \mu \mathrm{m}$ stainless steel sieve \& Sonic Sifter Separator, Advantech Manufacturing Co., USA). Bone powders were sterilized at $150{ }^{\circ} \mathrm{C}$ for $1 \mathrm{~h}$, rinsed in distilled water and incubated in $1 \%$ phosphoric acid. They were rinsed again in sterile distilled water, and sterilized at $200{ }^{\circ} \mathrm{C}$.

\section{Scanning electron microscope analysis}

The samples were coated with a thin layer of gold $(\mathrm{Au})$ by sputtering and then the microstructure of the surface of the samples were observed on a scanning electron microscope (SUPRA 40 VP FE-SEM) that operated at the acceleration voltage of $20 \mathrm{kV}$.

\section{Isolation of human bone-marrow stem cells (hMSCS)}

After informed consent according to a procedure approved by institutional review board at Stem cell technology research center, hMSCs were isolated from bone marrow aspirates of a donor which was a candidate for autologous cell therapy in our previous report ${ }^{13}$. $\mathrm{hMSCs}$ passage 2 were used in this study.

\section{In vitro cytotoxicity evaluation of the particles}

The bioglass and hydroxyapatite particles were first sterilized using autoclave and then dispersed in DMEM with the concentrations of 5,50,100 and $200 \mu \mathrm{g} / \mathrm{ml}$. The particles were placed in a $15-\mathrm{ml}$ tube containing DMEM. The dispersion of particles was performed using ultrasonic irradiation for $20 \mathrm{~min}$. Stem cells were seeded at an initial density of $5 \times 10^{3}$ per well in 24-well plates and cultured under DMEM containing particles. In 0, 24, 72, and $96 \mathrm{~h}$ after culture, MTT assay was performed to assess the viability of stem cells. In each time point, $50 \mu \mathrm{l}$ of MTT solution ( $5 \mathrm{mg} / \mathrm{ml}$ in DMEM) was added to each well $(n=4)$ followed by incubation at $37^{\circ} \mathrm{C}$ for $3.5 \mathrm{~h}$. For dissolution of the dark-blue intracellular formazan, the supernatant was removed and $200 \mu \mathrm{l}$ of DMSO (Merck) was added. The optical density was read spectrophotometrically at a wavelength of $570 \mathrm{~nm}$. The same procedure

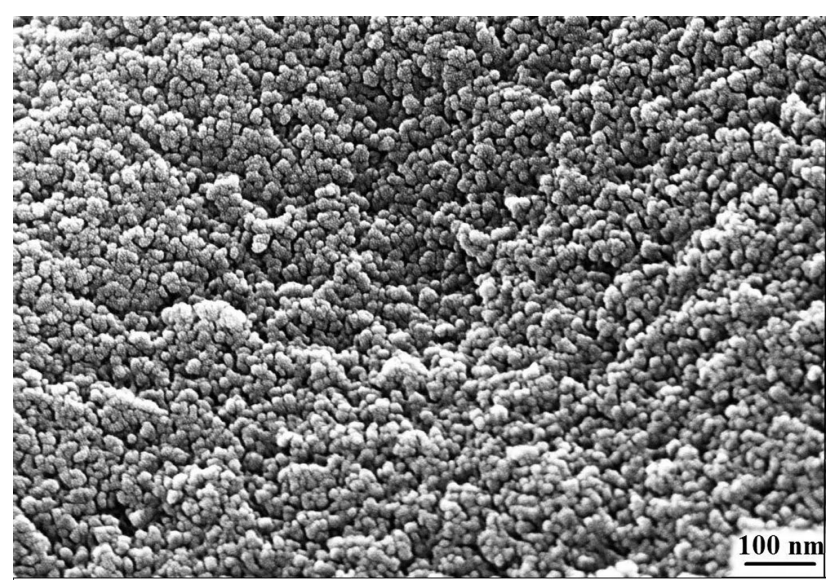

Fig. 2. SEM micrograph of the bioglass particles showed the particles were in the nanoscale range and agglomerated. 
Table 1. The optical density (mean value (standard deviation)) of DMEM containing different concentrations of bioglass 63S (BG) and bone-derived hydroxyapatite (HA) after 0, 24, 72 and $96 \mathrm{~h}$.

\begin{tabular}{|c|c|c|c|c|c|c|c|c|}
\hline \multirow{2}{*}{$\begin{array}{c}\text { Time } \\
(\mathrm{h})\end{array}$} & \multicolumn{9}{|c|}{ Concentration of bioceramic in DMEM $(\mu \mathrm{g} / \mathrm{ml})$} \\
\cline { 2 - 10 } & HA & BG & HA & BG & HA & BG & HA & BG \\
\hline 0 & 1.245 & 1.245 & 1.245 & 1.245 & 1.245 & 1.245 & 1.245 & 1.245 \\
\hline 24 & $1.217(0.2)$ & $0.972(0.1)$ & $0.854(0.1)$ & $1.002(0.2)$ & $0.98(0.12)$ & $0.948(0.1)$ & $0.964(0.14)$ & $0.936(0.1)$ \\
\hline 72 & $2.23(0.33)$ & $2.18(0.25)$ & $2.14(0.18)$ & $2.468(0.3)$ & $2.261(0.2)$ & $2.344(0.3)$ & $2.747(0.3)$ & $2.47(0.3)$ \\
\hline 96 & $2.877(0.2)$ & $3.834(0.35)$ & $4.634(0.3)$ & $5.35(0.4)$ & $5.794(0.4)$ & $5.5(0.3)$ & $5.181(0.22)$ & $5.718(0.5)$ \\
\hline
\end{tabular}

was performed for stem cells under particle-free DMEM as control.

\section{Statistical analysis}

All experiments were conducted at least for $n=3$. All of the data are expressed as mean \pm SD. One-way analysis of variance (ANOVA) was used to compare results. A p-value of less than 0.05 was considered statistically significant.
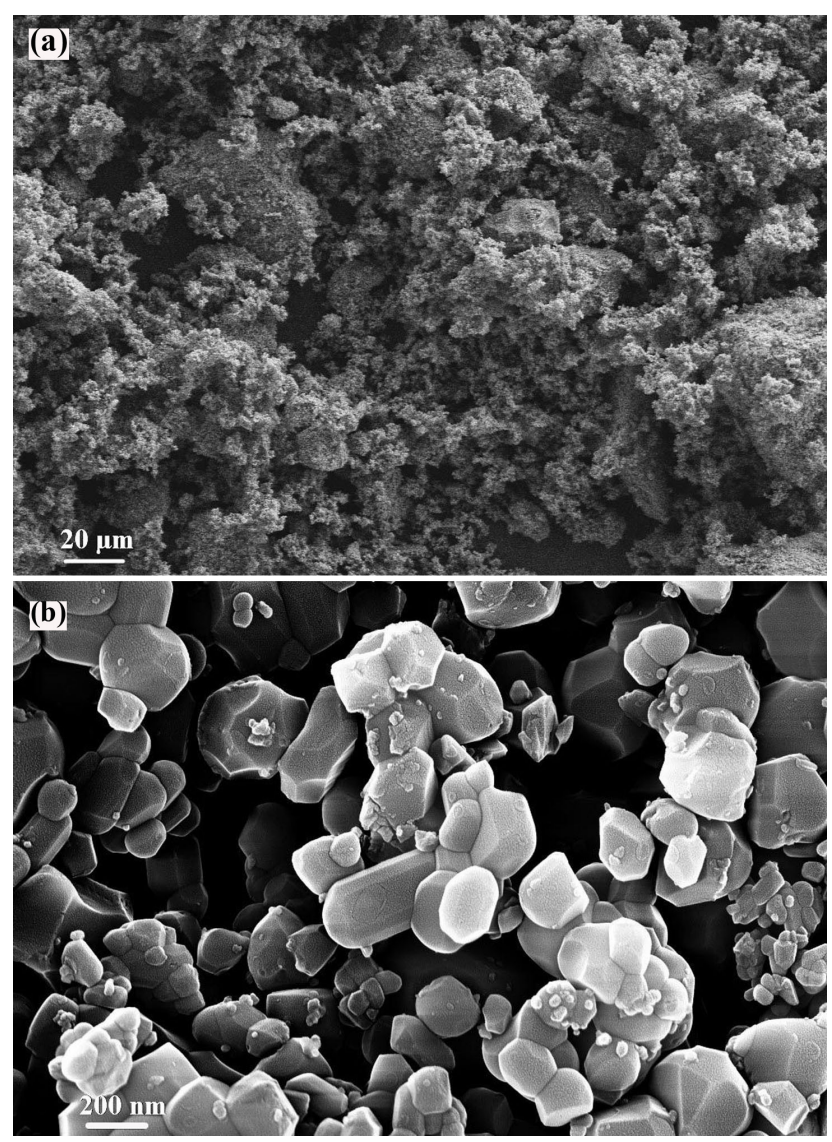

Fig. 3a. SEM micrographs of hydroxyapatite particles, showing the porous structure.

Fig. 3b. SEM micrographs of hydroxyapatite particles, showing variety in crystal shape and size within the particles.

\section{RESULTS}

Scanning electron microscope

Figure 2 shows SEM images of the bioglass particles. Heterogeneous surfaces consisting of random-sized particles can be seen. SEM confirmed particles were in the nanoscale range $(<80 \mathrm{~nm})$ but showed the particles were agglomerated. (Fig. 3a, 3b) show the microstructure of the prepared natural HA particles. The size of the hydroxyapatite crystals ranged from 50 to $500 \mathrm{~nm}$. For comparison, the HA crystal size in native bone have been reported to be in 20 to $40 \mathrm{~nm}$ range ${ }^{5}$. Thus, the crystal size in the bone-derived HA was somewhat larger than that of natural bone.

The effect of particles on the proliferation of stem cells

Table 1 shows the optical density values of DMEM containing different concentrations of bioglass $63 \mathrm{~S}$ and bone-derived hydroxyapatite after $0,24,72$ and $96 \mathrm{~h}$.
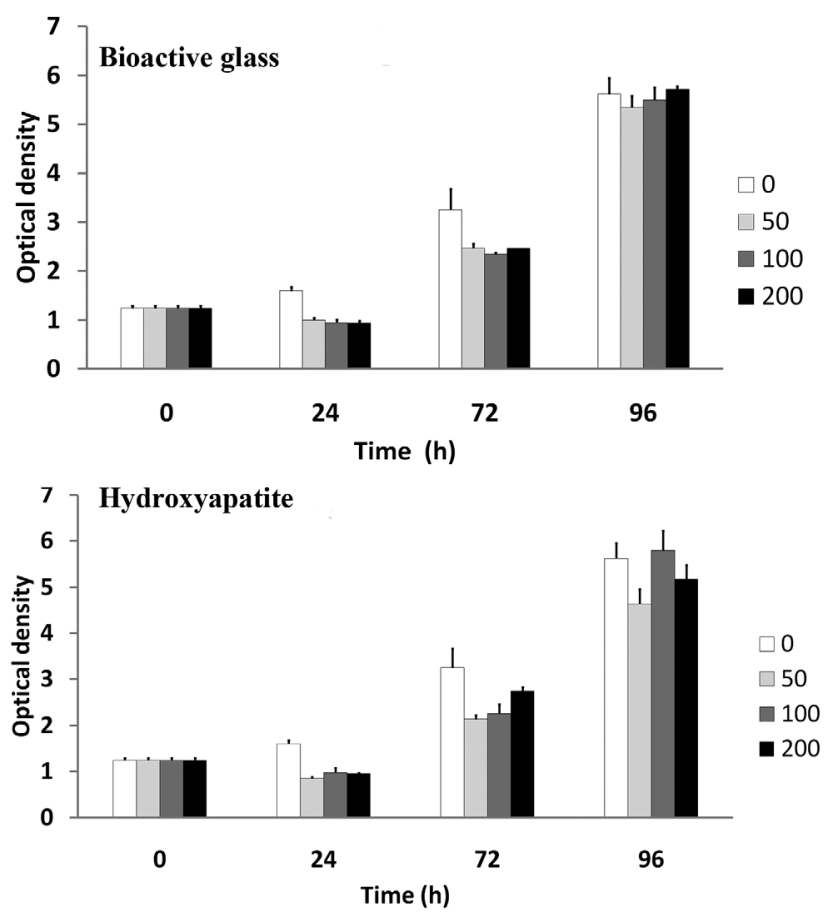

Fig. 4. The proliferation of hMSCs under different concentrations of particles during the time. 
During the first day, cell proliferation was observed only in the culture under particle-free medium. After this time, an increasing trend of cell number was measured during time in all cultures. After 72 h, stem cells cultured in particle-free medium showed the highest viability compared to that in other groups in both bioactive glass and HA-containing cultures. However, after $96 \mathrm{~h}$, there was no significant difference between the viability of stem cells in the groups with bioactive glass particles. However, in HA-containing cultures, higher viability of stem cells was detected in cultures under 0 or $100 \mu \mathrm{g} / \mathrm{ml}$ compared to other two groups (Fig. 4).

\section{DISCUSSION}

According to SEM image (Fig. 2), the prepared bioactive glass particles were less than $80 \mathrm{~nm}$. This result showed the prepared bioglass particles were very fine and highly agglomerated as well. These kinds of particles are expected to form through the sol-gel method ${ }^{12}$. It has been shown that the smaller bioactive glass particles, the higher bioactivity they have and are more suitable for biomedical applications ${ }^{1,2}$. According to $\mathrm{Hench}^{4}$, there is a genetic control of the cellular response to some kinds of bioactive glass materials such as $63 \mathrm{~S}$. Therefore, it would be a priority for this composition of bioactive glasses.

As shown in the SEM images (Fig. 3a, 3b), the crystal size of prepared HA was larger than HA crystals in natural bone. The much larger crystal size and the higher degree of fusion between individual crystals compared to the natural material are due to the manufacturing process ${ }^{7}$. The heat treatment at $700{ }^{\circ} \mathrm{C}$ for $2 \mathrm{~h}$ resulted in some sintering and crystallite growth ${ }^{7}$. The degree of crystallite fusion and growth, however, varied among different ceramic particles and even within one particle (Fig. 3b).

The biocompatibility and cytotoxicity of the novel biomaterials is a key issue that should be addressed prior to pre-clinical applications. In this study, the in vitro biocompatibility of fabricated particles was investigated via MTT assay. According to the gained results, except during the first day, stem cells proliferated in a similiar trend compared to control. The initial inhibition of cell proliferation may be due to the adoptation of stem cells to the new growth medium. However, the cyto-compatibility of particles can be inferred from the viability of stem cells in particle-containing medium compared to similiar to that in basal medium. These results confirmed that bioactive glass and bone-derived hydroxyapatite are compatible with human bone-marrow stem cells (hMSCs) and can be used for bone tissue engineering.

\section{CONCLUSION}

In the present study, we fabricated bioactive glass and bone-derived HA for bone tissue engineering applications. Furthermore, these particles did not show any cytotoxicity effect on hMSCs. Taking toghether, fabricated 63S bioactive glass and bovine-bone hydroxyapatite particles hold promising potential for application as the graft materials to enhance bone regeneration and repair.

\section{ABBREVIATIONS}

MTT, 3-(4,5-Dimethylthiazol-2-Y1)-2,5-Diphenyltetrazolium Bromide; DMEM, Dulbecco's modified eagle's medium; DMSO, Dimethyl sulfoxide

\section{REFERENCES}

1. Hench LL, Polak JM. Third-Generation biomedical materials. Sci 2002;163:51-9.

2. Hench LL. The story of Bioglass. J Mater Sci: Mater Med 2006;17:967-73.

3. Xynos LD, Hukkanen MVJ, Batten JJ, Buttery LD, Hench LL, Polak JM. Bioglass t45S5 stimulates osteoblast turnover and enhances bone formation in vitro: Implications and applications for bone tissue engineering. Calcif Tissue Int 2000;67:321-9.

4. Hench LL. Genetic design of bioactive glass. J Eur Cer Soc 2009;29:1257-65.

5. Rodrigues CV, Serricella P, Linhares AB, Guerdes RM, Borojevic R, Rossi MA, Duarte ME, Farina M. Characterization of a bovine collagen-hydroxyapatite composite scaffold for bone tissue engineering. Biomaterials 2003;24:4987-97.

6. Ruksudjarit A, Pengpat K, Rujijanagul G, Tunkasiri T. Synthesis and characterization of nanocrystalline hydroxyapatite from natural bovine bone. Curr Appl Phys 2007;8:270-2.

7. Haberko K, Bućko MM, Brzezińska-Miecznik J, Haberko M, Mozgawa W, Panz T, Pyda A, Zarębski J. Natural hydroxyapatite-its behaviour during heat treatment, J Eur Ceram Sci 2006;26:537-42.

8. Caplan AL. Adult mesenchymal stem cells for tissue engineering versus regenerative medicine. J Cell Physio 2007;213:341-47.

9. Deans RJ, Moseley AB. Mesenchymal stem cells: biology and potential clinical uses. Exp Hematol 2000; 28:875-84.

10. Li WJ, Tuli R, Okafor C, Derfoul A. A three-dimensional nanofibrous scaffold for cartilage tissue engineering using human mesenchymal stem cells. Danielson KG, Hall D, Tuan RS. Biomater 2005;26:599-609.

11. Arinzeh TL, Tran T, Mcalary J, Daculsi G. A comparative study of biphasic calcium phosphate ceramics for human mesenchymal stem-cell-induced bone formation. Biomater 2005;26:3631-8.

12. Fathi MH, Doostmohammadi A. Preparation and characterization of sol-gel bioactive glass coating for improvement of biocompatibility of human body implant. Mater Sci Eng A 2008;474:128-33.

13. Kharaziha P, Hellström PM, Noorinayer B, Farzaneh F, Aghajani K, Jafari F, Telkabadi M, Atashi A, Honardoost M, Zali MR, Soleimani M. Improvement of liver function in liver cirrhosis patients after autologous mesenchymal stem cell injection: a phase I-II clinical trial. Eur J Gastroenterol Hepatol 2009;21:1199-205. 